\title{
E-Notice Board (ENB) for the Faculty Community
}

\author{
Kingsley N. Omeje, Henry O. Osuagwu, and Chimezie F. Ugwu
}

\begin{abstract}
This research work developed Electronic Notice Board (ENB) for the faculty community. The purpose is to upgrade the already existing manual method of information dissemination, so as to improve the administrative work of the faculty, and to create an enabling environment for more efficient and friendly means of information delivery. It will improve the rate at which staff and students participate in faculty events and activities. The conventional notice board is one of the oldest methods used in information delivery and announcements to students. Students go to where the notice board is mounted in other to read updates or announcements. Use of wall notice board in every place is a tedious work since it needs to be updated regularly and with correct and right information manually. Few of the problems that necessitated the need for ENB are; inadequate time to read all the relevant information pasted newly on a notice board as a result of tight schedule since the copies are limited. Limited time-lag of newly pasted notice since people mutilate, remove or destroy the paper notices from the board leaving others uninformed. Some of the objectives are to enable individuals to view the update from their various devices from any location. To enable instant update to all users since notice is online. To allow individuals download and store copies of original information intact. Generally, it looks at the existing faculty notice boards, building a system that makes it run by the internet access or by local area network (LAN) so as to increase the rate at which relevant information is being disseminated to the faculty community with no location restriction. The user is kept updated each time the E-Notice Board is updated based on their categories through an SMS alert. This system intends to simplify and improve the University faculties to perform their daily activities since most of the school organs uses computerized system. This research work was designed using Object Oriented Analysis and Design Methodology (OOADM) and implemented using Hypertext Pre-Processor (PHP), Hypertext Markup Language (HTML), Bootstrap, Cascading Style Sheet (CSS) as front-end and My Structural Query Language (MYSQL) database as back-end.
\end{abstract}

Index Terms - E-Notice Board, Faculty, SMS, User Admin, User staff/students.

\section{INTRODUCTION}

One of the oldest methods used in delivering information and announcements to students in faculties is by conventional notice board. In order to read updates or announcements from the notice board, students would have to go to their faculties or departments where the notice board is located. But, as the world changes and new

Published on January 20, 2021.

K. N. Omeje, University of Nigeria, Nsukka, Enugu, Nigeria.

(e-mail: kingsley.omeje.pg83243@unn.edu.ng)

H. O. Osuagwu, University of Nigeria, Nsukka, Enugu, Nigeria.

(corresponding e-mail: henry.osuagwu.pg68120@unn.edu.ng)

C. F. Ugwu, Institute of Management and Technology, Enugu, Nigeria.

(e-mail: chimeziefedricku@ gmail.com). technologies have been discovered, the information delivery has also become more efficient and user friendly.

A Notice Board is a place where people can leave public messages. For example, to advertise things to buy or sell, a job opportunity, an upcoming event, a service, posters, memos, and company newsletters. Notice boards are often made of cork or other soft materials that allow pins to be fastened into them, to facilitate addition and removal of paper messages or it can be placed on digital devices such as computers, phones and other accessories were people can leave or erase messages for people to view [1], [2].

The growth and advancement in information technology has changed the way we live, communicate, learn and do business. As new generation of students embraced technology and some of them became attached to it, it is necessary to change the way information is being displayed, as it is often observed that whenever there is a change in seminar or class schedule, there would be some students missing the seminar or class because of not reading the notice board from time to time [3]. This indicates that the announcement system commonly used in many faculties or universities is somewhat ineffective when the message did not spread around to reach the desired students.

A Notice Board is a medium of communicating information to many people at the same time. It is widely used in educational institutions to display information regarding examinations, results, schedules and other curricular and extra-curricular activities [4]. In any faculty there is a lot of wall notice boards placed on different location where people with announcements typed or written on a sheet of paper can place it on the notice boards for other people to read when passing through those locations. Thus, there is a lot of accumulation of littered papers due to carelessness of people who place them and no one is responsible for removing or cleaning them [5]. Also, the announcement may not reach the intended, as others may not pass through the notice boards. Sometimes, weather condition may affect peoples' movement; some people may not live within the schools premises, so it becomes difficult for them to see the announcements on time. And hence there is a lot of strain on the people who intend to make announcements thereby they place it everywhere in bid to get to the desired audience. All these happens because the ENB is not used in this context [6].

The advent of internet technology enables one to access information from any location once one is connected. In the past, institutions especially academic ones have been throttled to posting notice messages physically on notice boards. But presently, every advertisement goes electronic or digital. Some large shopping malls and shopping centers are using the digital moving displays [7]. The traditional notice board are now been replaced with the electronic notice boards. while the traditional notice board are made of 
materials like hardwood, aluminum and other hard surfaced media which allows written objects to be pasted or mount on them; the electronic notice board comes in form of energy powered devices, e.g. Global System for Mobile (GSM) or Liquid-Crystal Display (LCD). Electronic notice board could be wireless or non-wireless device.

Information dissemination should best be done with the internet since we are in the age of information technology [8]. The aim of this research work is to specifically develop an online Electronic Notice Board (ENB) for the faculty community. Identification of the drawbacks of the existing manual notice board system leads to the designing of the $\mathrm{ENB}$, this should make information dissemination much easier and improve the administrative work of the faculty community. It will also improve the rate at which staff and students participate in faculty events and activities since awareness depends greatly on the effectiveness of information delivery.

The rest of the paper will be discussed in the following order: Section II presents the related works. In section III, analysis and the design of the proposed system was explain. Section IV presents the system development and implementation. Conclusion are contained in section V.

\section{RELATED WORKS}

Modern lifestyle urges everything to be fast and efficient even in information delivery. Information technology applies various tools and methods to achieve the objective of delivering information in time, accurate and effective [9, 10]. Online communication makes retrieval of information and feedback fast from around the world.

Today students communicate more online than they do in face-to-face. This was reaffirmed by [11] that university administrators should be alert of this phenomenon and learn to use the variety of electronic media available in positive ways to stay connected to faculty social networks or to promote relevant events on campus. The trend in Information Technology (IT) presence has shown that the world is becoming increasingly digital with all its operations being converted from manual to computerized systems. Every organization ought to follow the trend or miss out due to inability to cope with effective and efficient use of computerized systems, notice board not an exception. Technology in information delivery according to [8]-[10], information and communication technology (ICT) and development in modern technology bring out important changes in the process of acquiring, storing, processing, retrieving and delivering the information generated constantly across the globe in the universe of knowledge over multidisciplinary fields of study.

The work by [11], suggested that faculties should use the most popular technology among students. It should be user friendly, efficient and relevant to today's world. They highlighted the use of Facebook, as one of the most popular online social media tools among students. It allows users to connect to a large group of people with one login on one website. The two-way communication feature makes it suitable for faculty-students or university-students interaction. Faculty can upload announcement, updates information or news and students can always inquire doubtful itinerary of information or simply 'like' the message to show their agreement or preference.

The usefulness of location as a constraint for information distribution is perhaps best seen when it is removed: now we can contact almost anybody any time and instantly access information everywhere we are beginning to experience information overload [12] and communication overflow [13]. Extensive research has been done on how to support informal communication using IT. However, in most cases the aim has been to support distributed rather than colocated groups [14]-[17]. The rationale for this is that many incitements for occasional communication are lost when people are not co-located. Thus, support for awareness about peoples' whereabouts that could compensate for not having corridors, lunchrooms etc. as sources of such information have been developed. The notion of proximity has also been used as a metaphor in virtual environments designed for social interaction, for instance Chat Circles and FreeWalk [17], [18]. One of the main differences between these researches and the work presented here is that in a wall notice setting, the technology does not mediate the information. Therefore, our focus has been on how to support information distribution, for instance by means of providing or getting instant update and relevant information [19], [20].

The above shows the downsides of conventional notice board, as a flat solid object placed at strategic positions where information and posters are placed [1], [21], it is required that old notices be removed before new one are pasted; if not, the board will be littered with both relevant and irrelevant massages. Going through the whole notice board searching for relevant information may be time consuming and as a result, students might overlook some of the new notices on display. More so, the process of sticking notices on a day-to-day basis is tedious and time consuming which led also to wastage of paper [4].

The work in [3], points to an obvious flaws in the use of the conventional notice board as a tool for information delivery since it is not accessible everywhere at any time. Students need to plan their ways as they go back and forth to read the information on notice board from time to time from the notice board which is located at the faculty, department, corridors, and some other locations; this is time and energy consuming. As a result, the information delivery will be limited and ineffective [22].

The consensus among communication officers is that notice boards have been overlooked as a communication tool. This is partly due to the number and spread of notice boards; the distances involved can make maintenance timeconsuming and difficult. Observing notice boards untouched reveals many examples of boards that contain too much information, which can be confusing, and lack coherence in the type of information they contain. Often, there is no clear 'owner' of the board and anyone is free to post material at their own discretion [22]. This user-generated entropy can result in information overload that limits the effectiveness of notice boards for communicating. The excessive dependence on this practice in universities is still not enough to circulate relevant information around.

Giving an instance [23], there is nothing more frustrating than trawling through social networking sites or searching 
on campus notice boards for the things you need. Notices on University Board are listed according to categories, making it as easy as possible for people to find what they are looking for. The unique thing about 'University board' is that it works just like a conventional notice board. We have taken the traditional wall-based notice board concept, and made it available online. Because it is now online when searching for an item, it will be easy to get.

In order to overcome these drawbacks, the concept of wireless notice board was introduced. In a wireless notice board, only an authorized person can send a message from his mobile phone irrespective of his location from the display device [4], [21]. Pinning a document on the board creates a reminder that attention needs to be paid to a particular piece of information on paper by making it highly visible, for example, an electricity bill that needs to be paid in the following week, a scholarship examinations that needs respond. Notice boards have become a way to efficiently organize way of life without paper-based documents. This motivated the need to improve the functionality of traditional notice boards in other to build more powerful applications [2].

In order to improve the effectiveness of conventional notice board, [24] suggests replacing the traditional cork board or complementing it with a virtual notice board that can be accessed through web pages. This board could be divided into different sections, such as 'Events and conferences', 'Grants', ‘Administration', 'Library', 'Exam calls', 'Teaching' and 'Work offers'.

Conventional and web base notice board were examined to know which method the students preferred to receive information or announcements by [3]. About (53.4\%) of the students choose virtual notice board while $28.9 \%$ of them were in favor of the conventional notice board. However, $17.7 \%$ insist on the use of both types of notice board as shown below.

\begin{tabular}{ccc}
\multicolumn{3}{c}{ TABLE I: PERCENTAGE OF STUDENTS' NOTICE BOARD PREFERENCE [3] } \\
\hline Students' Preference & Frequency & Percentage (\%) \\
\hline $\begin{array}{c}\text { Change to virtual notice board } \\
\text { Remain to use conventional } \\
\text { notice board }\end{array}$ & 190 & 53.4 \\
$\begin{array}{c}\text { Use both conventional and } \\
\text { virtual notice boards }\end{array}$ & 103 & 28.9 \\
\hline
\end{tabular}

The Study by [3], also reveals some important findings; that students are really interested on virtual notice board and tend to use the internet during their spare time. They have the tools to go online and stay connected to the internet. $90.7 \%$ of them have computer or laptop, $42.5 \%$ have their own internet broadband and Wi-Fi Hotspot are also available at various locations on campus. The author concluded that in order to encourage and attract more students to read updates and announcements from notice boards, a new and creative way of delivering information should be adopted. The idea of sharing information easily and quickly should be the basis for finding the best solution for an effective information delivery. In order to enhance students' participation, the information should reach the students.

Result of the work done by [25], observed 20 random users who happened to pass by the display installed in the secondary entrance within half an hour. Only one user watched the display for about one minute. 10 others glimpsed at the display for about two seconds, and 9 users did not look at all. Messaging is a key part of the mobile experience [26]. In 2010, Americans sent and received over 2.1 trillion text messages on their mobile phones. Worldwide, it is estimated that active mobile messaging users outnumber email users two to one, making mobile messaging perhaps the most pervasive, effective communication channel today [27]. Using API, TextMarks also lets you send SMS messages to your subscribers at any time, and you can send messages to all subscribers at once or one at a time. With the TXTImpact SMS API, one have access to powerful text messaging functionality for integrating into your existing and new web and enterprise application [27]. With SMS protocol integrated in the notice board, will enable messages to be sent to user device each time there is update in the system.

To move people to friendly interaction, [28] suggest the interface should clearly convey low commitment interaction that is quick and enjoyable. Our challenge is to decrease barriers to interaction on the notice board in order to grow participation and the capacity to support the faculty community communication in the long-term. We have observed that people prefer to interact with the notices with an object on the notice board rather than only text based navigation, and prefer to interact with image notices rather than text focused notices. These observations led us to improve the interface display to accommodate images and discover other means of engaging people in creating notice board content of interest for the faculty community.

The use of Bluetooth announcement system was suggested by [29] as a replacement for both the conventional and the electronic display system; even though the electronic notice boards seem more effective compared to the traditional. Because the electronic allows the end user to quickly and easily update information in real time while the traditional notice board is not omnipresence, students still need to pass through the physical location of the board in order to read updates. On the other hand, Bluetooth system, allows transfer of information only when the Bluetooth is activated and within the coverage area. However, the Bluetooth has its disadvantages. It is prone to virus, energyconsuming and weak security facilities since hackers can penetrate and access any shared data without permission of the original owner.

[8], [30], [31] suggests improvements to wireless notice board to replace the conventional notice board; a display device using microcontroller was adopted. A VGA slid form display device the size of a desktop screen was used with a GSM compatible with any network provider. The text transmission process firstly required message to be transmitted from the user and received with GSM at the receiver's end. The content of received message is converted into hexadecimal numbers of their ASCII value and then to stream of bits. These received streams of bits are then converted into the hexadecimal number and then to the actual message to be displayed on the LCD screen by using VGA cable. Only the authorize person can send a message from his mobile phone irrespective of his location from the display device. [32], [33] also proposes a LED display board 
with dual power supply such as solar and AC power and changing the displaying message either by laptop or SMS through mobile phones.

In [34], the Virtual Notice Board was developed using Visual Basic. This program is based on Computerized Notice System that stores information about the notices of the chief, officials and faculty members of an organization. In order to view and post notices the chief, officials and faculty members each must create a valid account and only then they can generate notice and also they can edit or update notice. After selecting a notice, members can view it through the form with data table and many more.

Also the Notice Board Pro which is an online application written in PHP and MySQL by [35] was reviewed. The Notice Board Pro is an application that enables users to create and view items that have been created by other users. Users can use the notice board to, for example advertise a car for sale, a room to rent, a fridge to sell, a service and so on. When viewing items you can choose to view all the items on the notice board or, alternatively, only those items that fall within a particular category, say vehicles, household items or accommodation, or perhaps all three. To create an item yourself, you need to be registered and signed in.

Padmashali et al. [36] asserts that the problems faced by convectional notice boards could be resolved by the implementation of Electronic Notice Board application on which the time wasted in pasting paper notices will be saved. Only the authorized user can upload the notices of different categories which is recommended and approved by the higher authorities. Viewers then have privilege to view notices and download update irrespective of their locations. Unified Modeling Language (UML) was used in the application.

In [37], an electronic bulletin board which can be accessed by members of a family from their wireless devices was developed. The wireless devices for various members of the family can access a common database, which produces an appearance of a bulletin board having notes attached thereto. The notes may be generated manually, may be generated from e.g. a calendar, or may be the result of a short message service contact. The notes may be of various colors to indicate their origin or importance. The notes may be moved around on the board and any member of the family may generate new notes.

But since our focus is to grow participation in order to increase the capacity for an inclination of accessing faculty community information [17]. The notice board is assessable online using the link integrated on the SMS sent to user device to allow rapid perusal of faculty notices. In the end, it does not really matter whether Facebook, Bluetooth, Liquid Crystal Display (LCD), Wireless notice board, or a web page that function as the virtual notice board announcement system; what matters the most, is for the information to reach the students. However, the virtual notice board is seen as the best option to carter for the needs of the students right now. Researchers strongly believe that faculties that need to communicate to a large number of students, no matter whether to make announcement or to update latest information, should be using the virtual notice board. The use of virtual notice board will lead to a much more efficient information dissemination rather than heavily rely on the conventional notice board.

\section{ANALYSIS AND DESIGN OF THE PROPOSED SYSTEM}

The goal of this analysis stage is to truly understand the requirement for the new system in other to develop an upgrade system. This work uses the object-oriented approach. The methodology employed is object-oriented analysis and design methodology (OOADM). OOAD is a software engineering approach that models a system as a group of interacting objects. Each object represents some entity of interest in the system being modeled and is characterized by its' class, state (data element), and behavior. A concept in the object-oriented approach enables analysis to break a complex system into smaller manageable modules, work on the modules individually and easily place the modules back together to form an information system. A set of diagrams or models is used to represent various views and functionality of the system and is commonly known as Unified Modeling Language (UML).

\section{A. Analysis of the Existing System}

The existing system makes use of the manual method of physically passing information around in the faculty. Their processes include the following:

- Notice boards are developed and placed in a specific location in the faculty.

- information is prepared by selected individuals or groups in the faculty.

- Messages are manually pasted to the notice board in the faculty or departments.

- Students physically go to the notice boards to read notices.

Looking at the notice board in situ, the following problems were identified in the existing system:

- The whole process of removing the old notice to paste the new notice on the notice board is time consuming.

- It is energy consuming to always go back and forth to read the faculty notice board on regular basis.

- It is not accessible everywhere at a time.

- People mutilate, remove or tear-off notice from the notice board leaving others uninformed.

- There is unregulated display of information.

- Leads to littering the school compound with pieces of papers.

- Difficulty in storage and no efficient reference to past relevant information posted.

- No designated principal in charge of the board since anyone is free to paste materials at their own discretion.

\section{B. Analysis of the Proposed System}

The proposed system in this research is an E-Notice Board. This system is a web application which is engaged in providing up-to-date articles and notices and other information for all the users associated with the faculty community. The faculty notice board system will take care of the problems identified in the existing system. All the updates like add, delete, view are done by the administrator, so that user will get the update of the current messages 
through SMS alerts. We intend to run the ENB as a program that can be viewed anywhere and anytime. For the fact that the notice board program runs on personal computers as well as mobile phones, information dissemination is efficient.

\section{Requirement Specification}

Unified Modeling Language (UML) was used in this work; it is a graphical language for visualizing, specifying, constructing, and documenting the artifacts of a software intensive system. The UML offers a standard way to write systems' blueprints, including conceptual things such as business processes and system function as well as concrete things such as programming language statements, database schemas and reusable software components. UML diagrams represent two different views of a system model: UML Behavioral diagrams and UML Structural Diagrams.

UML behavioral diagrams visualize, specify, construct and document the dynamic aspects of a system. Behavioral diagrams used are as follows: use case diagram and activity diagrams. Whereas UML structural diagram emphasizes the static structure of the system. It includes class diagram, component diagram and deployment diagram.

\section{Use Case Diagram}

Use case diagrams shown in Fig. 1 are central to modeling the behavior of the system, subsystem. These are important for visualizing, specifying, and documenting the behavior of an element. It shows the set of use cases and actors and their relations. This organizer consists of an actor called user and use cases.

Users:

There are about four users. They are: i) Academic Staff, ii) None Academic Staff, iii) Students, and iv) Administrator.

The registered users can login to the ENB. After logon, the students can access all details of the information on the news notice, sport notice and academic notice on the faculty notice board and logout. But the staff after logged in, can access the details information on the staff notice and all other categories of notice board on the faculty ENB. All user have access to create notice and forward to the admin for approval, admin upload the notice based on its category and all registered members will receive a short message sent on their device in form of real-time SMS; alerting them about new update on the online notice board also giving them hint of the message and granting them a link to access the notice at their own convenient time.

\section{Administrator:}

The administrator is the user who is responsible to maintain the flow of the messages on the notice board. $\mathrm{He}$ performs update to the database.

The following use case are invoked by the administrator:

- Add or delete notice.

- Edit and update notice.

- Logout.

The administrator is the only person allowed to add or delete notice on the notice board. He is also allowed to edit and make changes to the notice board if needed. The administrator logs out after performing the required update.
The server verify login and grant access to authorized users. It also forwards a short message to users' device in form of real-time SMS; alerting them about new update on the online notice board also giving them hint of the massage and granting them a link to further investigate the information if they are directly concerned. User can then go online at their convenient to read the notice in detail.

\section{E. Activity Diagram}

The Activity diagram shows a graphical representations of workflow of stepwise activities and actions with the available of input in the faculty ENB. The activity diagram for the user registration is showing in the Fig. 2 below.

\section{F. Activity Flow Diagram}

Activity Flow Diagram (AFD) is the logical representation of the data flow of this work. The activity flow diagram in Fig. 2 depicts the stepwise activities of all users in the ENB after registration. Fig. 3 shows the AFD's of the proposed system, where by the flow of data from external entities into the system and how data moved from one process to another is well elaborated.

This information system adheres to all crucial nonfunctions like, accessibility, reliability, portability, interface and security. As it works in Faculties it has been designed to be accessed by large number of people at the same time. It is capable of storing the posted notice and allow free download for users. The application is developed by using PHP. Developed in PHP and MYSQL as is database found in, make it to run on Windows and other operating system provided. Its interface can be easily accessed through internet explorer, Mozilla Firefox and any other windows and Linux browser that is compatible with the scripting language used in developing the system. For security, all registered users will login to the system using their registered username and password.

\section{G. Class Diagrams}

The purpose of a class diagram is to show the classes within a model. In an object oriented application, classes have attributes, operations and relationships with other classes. The class diagram is used to describe and show the necessary relationships among the tables, which are selected to store the data persistently in the system. Fig. 4 depicts the class diagram.

\section{IV.DEVELOPMENT AND IMPLEMENTATION}

This system is a menu driven web application, such that the user requires logging in so as to have access to their various privileges and to move from one page to another to get their required information.

Implementation refers to the activities that occur after the software has been developed and tested in the development environment. These activities usually comprise data conversion, system testing, user manual/training, performance evaluation and change over procedure. 


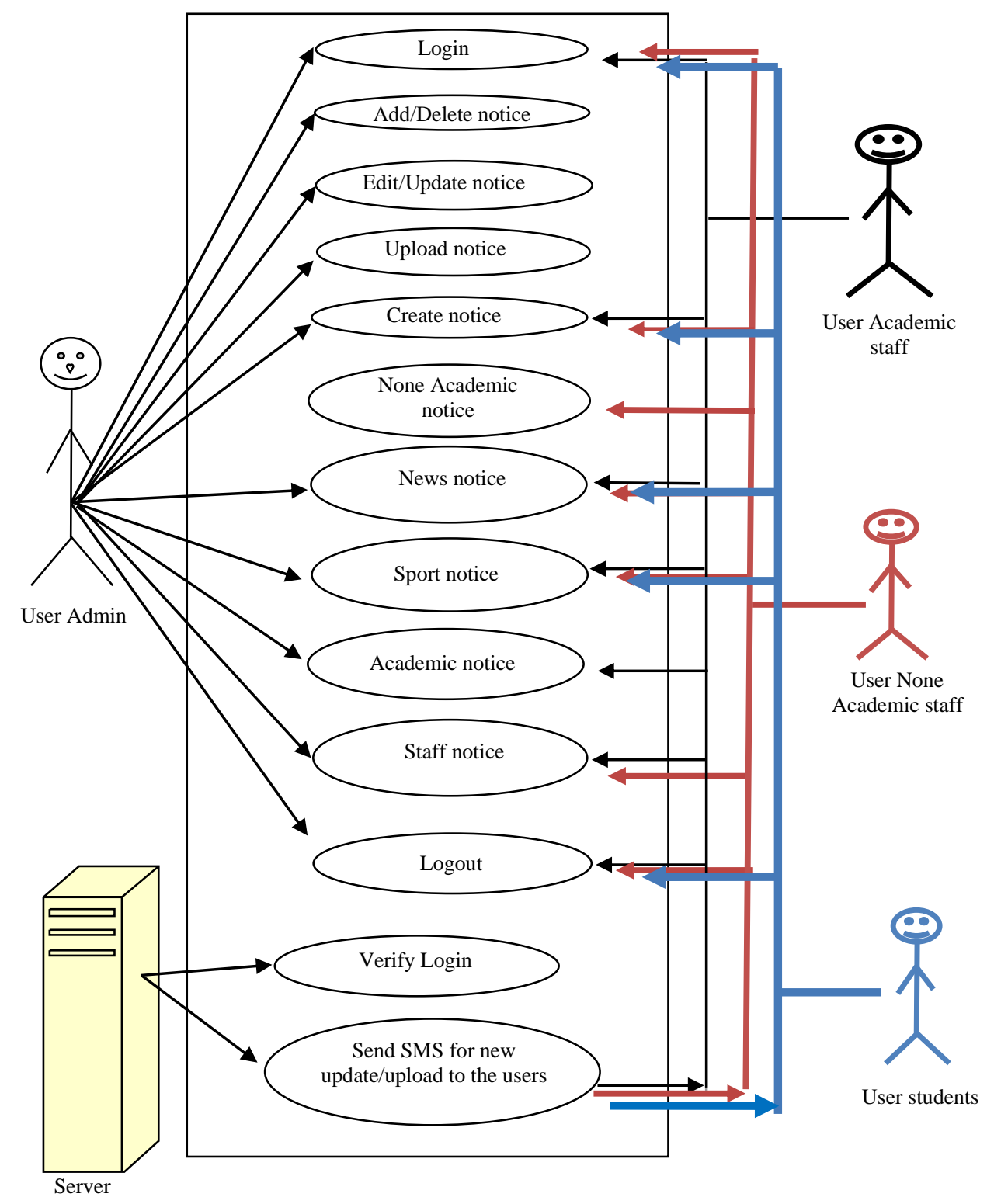

Fig. 1. Use Case diagram.

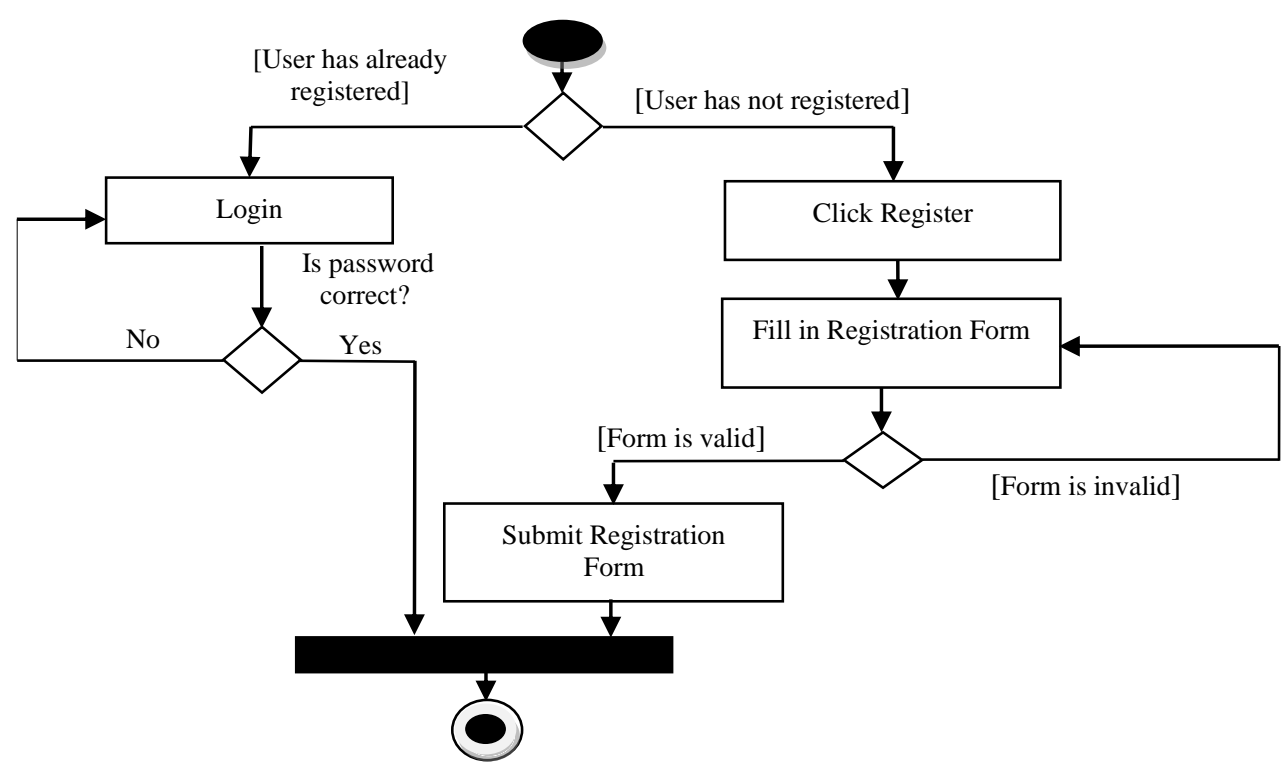

Fig. 2. Activity diagram for user's registration object. 


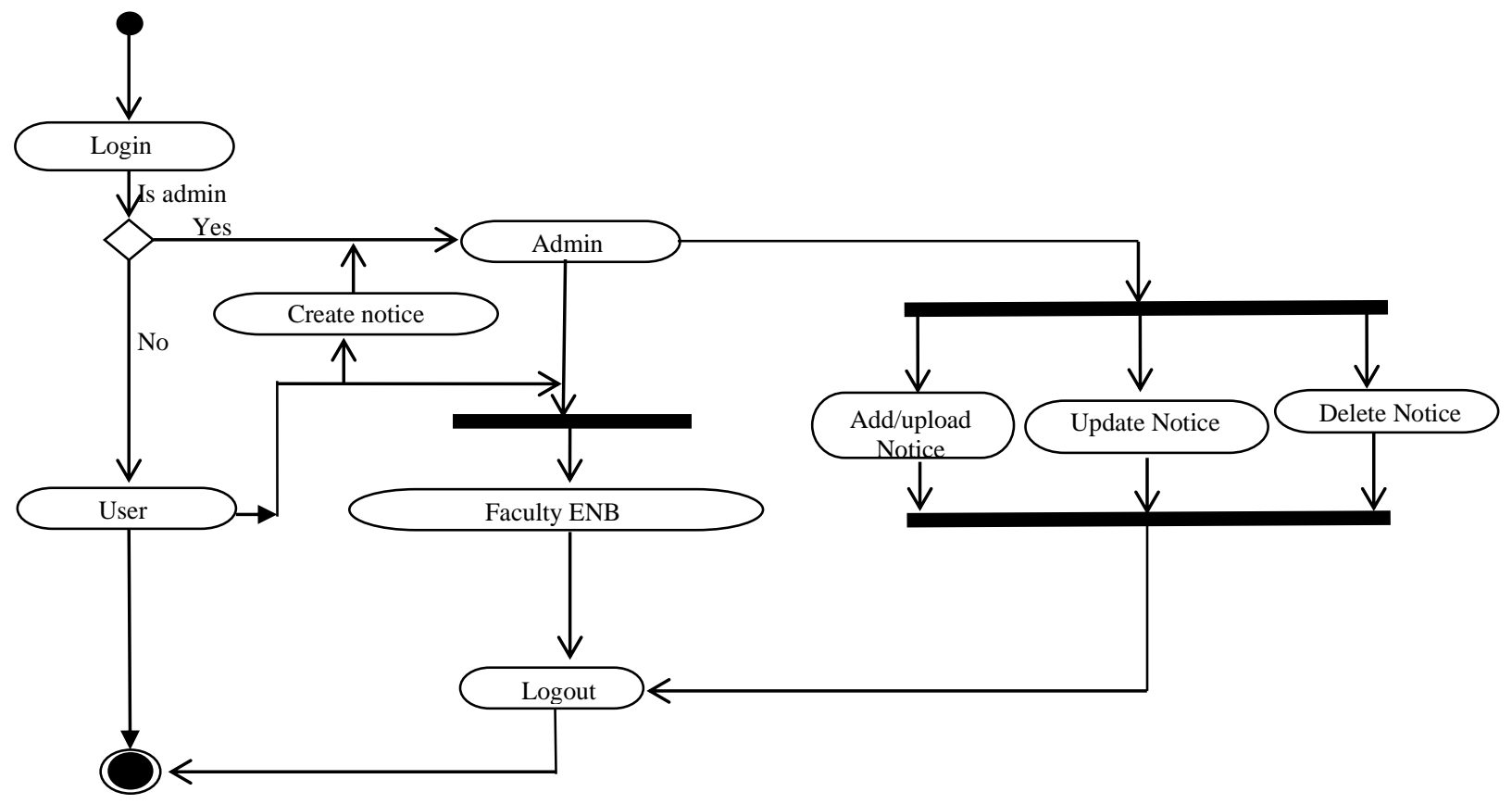

Fig. 3. Activity Flow Diagram for the System.

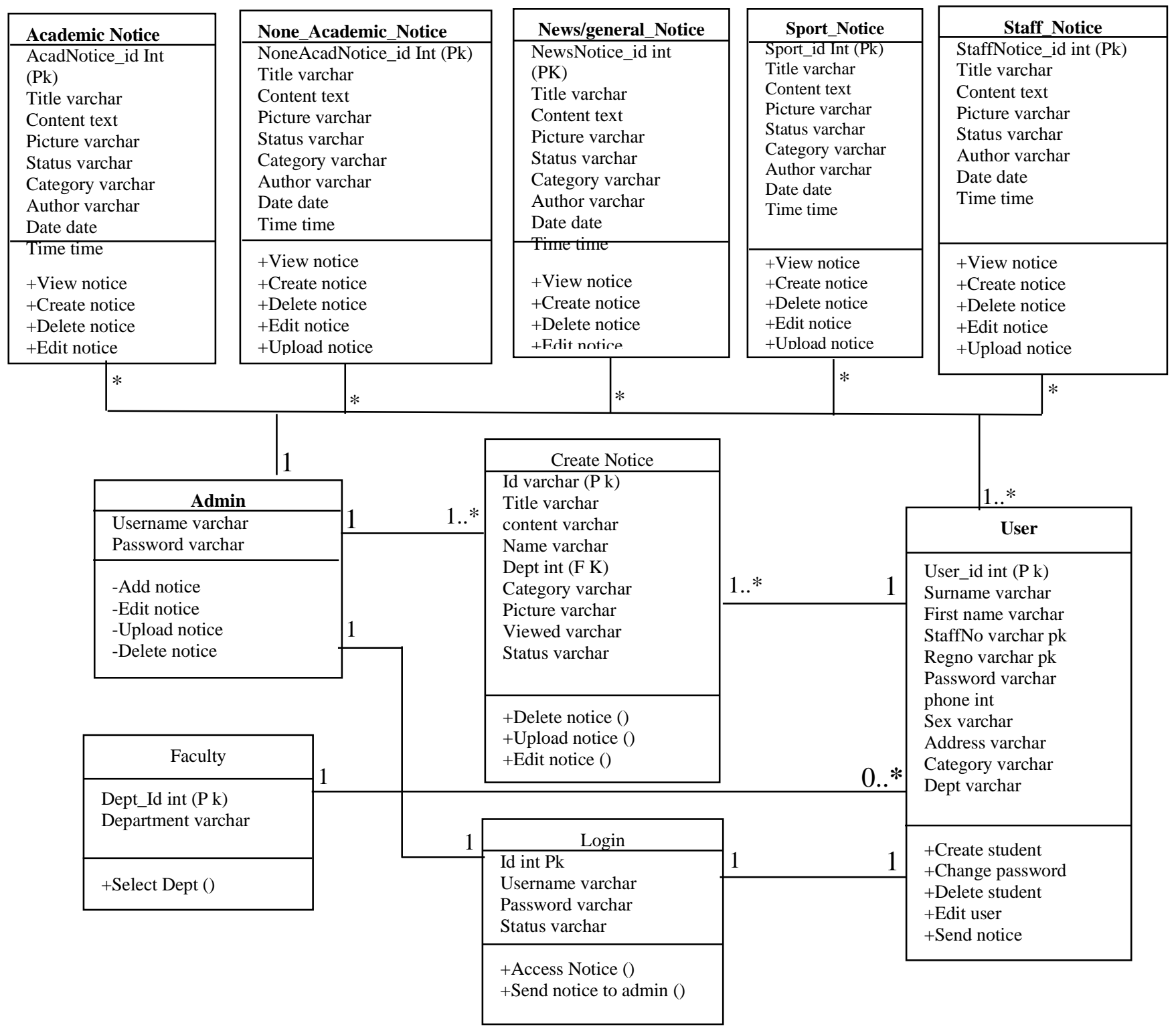

Fig. 4. Class Diagram. 


\section{A. Hardware and Software Interface}

TABLE II: HARDWARE/SOFTWARE INTERFACES Minimum Hardware Requirements

\begin{tabular}{|c|c|c|}
\hline \multicolumn{3}{|c|}{ Minimum Hardware Requirements } \\
\hline $\mathrm{S} / \mathrm{N}$ & Server-Side Specification & Client-Side Specification \\
\hline 1. & $2 \mathrm{GHz}+\mathrm{CPU}$ speed & $1 \mathrm{GHz}+\mathrm{CPU}$ speed \\
\hline 2. & 2GB+ of RAM & $512 \mathrm{MB}+$ of RAM \\
\hline 3. & 10GB + database space & $512 \mathrm{MB}+$ hard-drive space \\
\hline 4. & 20GB+ hard-drive space & $\begin{array}{l}\text { Internet connectivity (400kbps+ } \\
\text { bandwidth) }\end{array}$ \\
\hline 5. & Web server (HTTP/FTP) & Personal Computer (PC) \\
\hline 6. & Database server (SQL) & \\
\hline 7. & Webmail server (SMTP) & \\
\hline \multicolumn{3}{|c|}{ Minimum Software Requirements } \\
\hline $\mathrm{S} / \mathrm{N}$ & Server-Side Specification & Client-Side Specification \\
\hline 1. & Linux ${ }^{\circledR}$ or Windows ${ }^{\circledR}$ OS & Linux ${ }^{\circledR}$ or Windows ${ }^{\circledR} \mathrm{O}$ \\
\hline 2. & $\begin{array}{c}\text { Apache }^{\mathrm{TM}} 2.0+\text { server (PHP } \\
5.0+)\end{array}$ & JavaScript-enabled web browser \\
\hline 3. & MySQL'M 5.0+ server & \\
\hline 4 & Mercury $^{\mathrm{TM}} 4.0+$ server & \\
\hline
\end{tabular}

\section{B. Communication Interface}

(i) TCP/IP (Transmission Control Protocol/Internet Protocol);

(ii) HTTP (HyperText Transfer Protocol);

(iii) HTTPS (Secured HyperText Transfer Protocol);

(iv) FTP (File Transfer Protocol);

(v) SMTP (Small Mail Transfer Protocol); etc.

\section{Software Development Models and Implementation}

(i) Waterfall model; and/or

(ii) Rapid Application Development (RAD) model.

\section{TABLE III: SOFTWARE DEVELOPMENT/IMPLEMENTATION}

\begin{tabular}{ccc}
\hline S/N & Front-end Specification & Back-end Specification \\
\hline 1. & HTML 4.0+ & MySQL 5.0+ \\
2. & CSS 2.0+ & PHP 5.0+ \\
3. & JQuery 1.8+ & JQuery 1.8+ \\
4. & JavaScript 1.5+ & JavaScript 1.5+ \\
5. & Adobe Photoshop 7.0+ & RSS 2.0+ \\
\hline
\end{tabular}

\section{System Maintenance}

Routine maintenance checks and application upgrade shall be the full responsibility of the web administrator. The database administrator shall be responsible for performing routine database backup/recovery and optimization operations on the database server to boost its effectiveness and efficiency.

\section{E. User Characteristics}

(i) Technical Expertise: Users ought to be computer literates and be able to use web application.

(ii) Educational Level: Users must, at least, be an undergraduate student; a basic understanding of English Language is very necessary.

(iii) Experience: Users must be conversant with his/her institution's rules and code of conduct.

\section{F. Constraints}

(i) Additional network-security strategies or policies have to be imposed on the system application when it is deployed to a live server. This will protect vital data and information from unauthorized application/network access (data theft).

(ii) To improve application security, it may be helpful to deploy the system application on an intranet or extranet. However, the application can also be deployed on the Internet.

\section{G. Assumptions and Dependencies}

(i) The system application is intended for the staff and the students within the faculties

(ii) Users of the system are bona fide staff and students of the institutions which operate on the application.

(iii) All users are computer literates.

\section{H. Systems Modules}

Modularity is an important concept of Object-Oriented Programming (OOP). A module is a functional component of a system developed separately. Module of a system are independent of one another but communicate with one another and can be composed into a larger system.

Every user of the system shall have his/her own account in which all operations and services of the system entitled to will be performed there. Though there is no definite level of clearance among users, but still there is difference between the created accounts for administrators, staffs, and students. So there are three modules in the system:

\section{- User Registration module}

The user in this module are the staff and students who fill the relevant information needed to be captured. If the submitted record is valid, it creates the user record in the database. It is necessary for a user visiting for the first time to register in order to login and access the system. (See Fig. $8)$.

\section{- User Login Module}

There are 2 sub-modules in this module.

1. User Login Module

2. Administrator Login Module.

The user login module captures relevant data of the successfully registered user which involves the username and the password in order to grant the user access to the system. Fig. 5 shows the user login module.

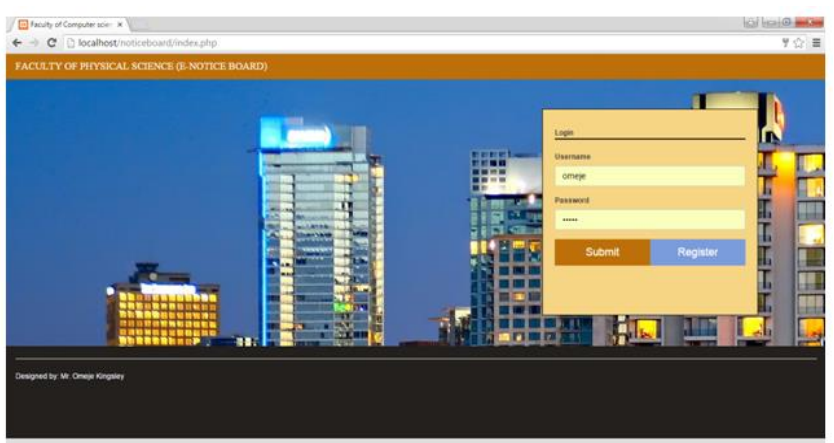

Fig. 5. User Login Module.

The administrator login module captures the administrator's data which includes the username and password send to the saver for authentication in order to grant the administrator access to the system (See Fig. 7).

\section{- Faculty E-Notice Board Module}

The faculty notice board module allows the user to access different category of notice board and also send notice based on the categories (academics, news, sport news and staff notice) to the administrator to upload on the notice board since all updates are perform by the administrators. Fig. 6 shows the faculty E-notice board module. 


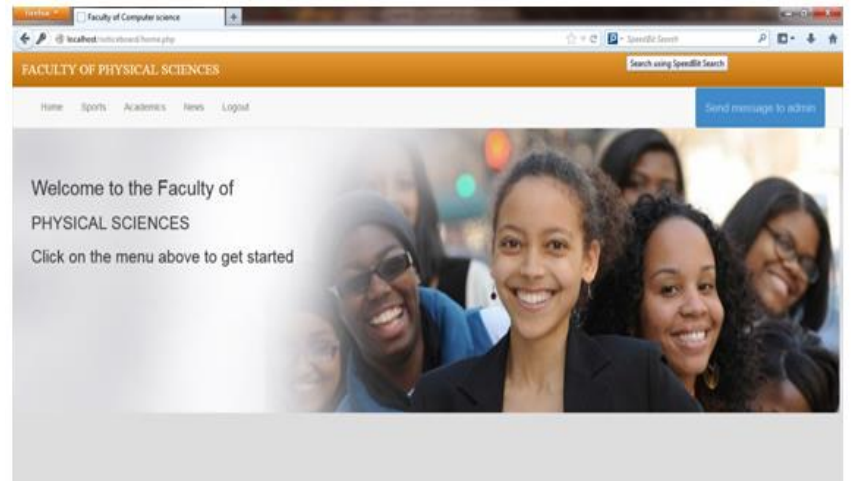

Fig. 6. Faculty E-notice board.

\section{Performance Evaluation}

The performance of this new system was extremely excellent and it has proved its reliability through successful application of test data and eventually generation of result exactly as expected output. Consequently, the software evolution is a successful one because actual test result yielded both design specification and performance capabilities. In other words, since the actual test result satisfied the expected test result, it means that the software packages objective is achieved. Fig. 7 below shows the screenshot of the administrator's login page.

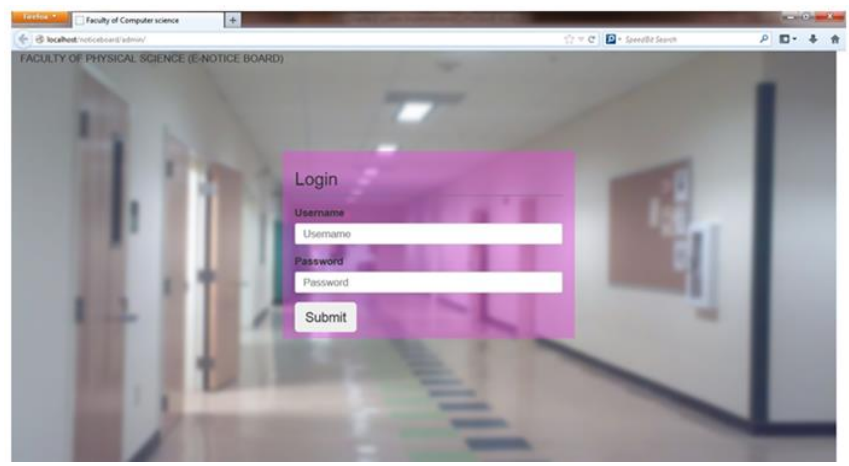

Fig. 7. Administrator's login page.

The Fig. 8 below is the registration page where user (staff /students) can register to have access to the notice board through its username and password, and will be able to receive SMS alert message when any update is made to the system. The category option in the registration form enables the user to have access only to its own category (students/staff) on the notices board.

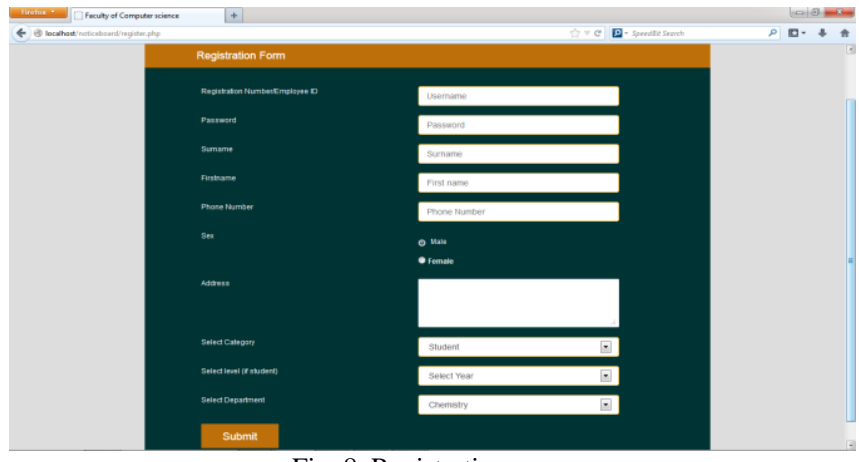

Fig. 8. Registration page.

The Fig. 9 below is the home page of academic staff notice board which staff can access; staff notice, students notice, sport notice and forward notice to admin for uploads.

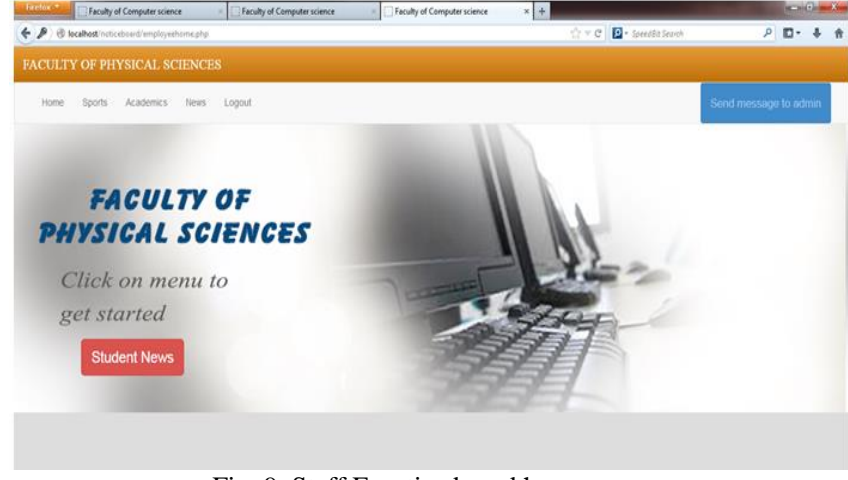

Fig. 9. Staff E-notice board home page.

The Fig. 10 below shows user input form for creating notice, the user select category from the form based on the type of notice to be submitted to admin for approval.

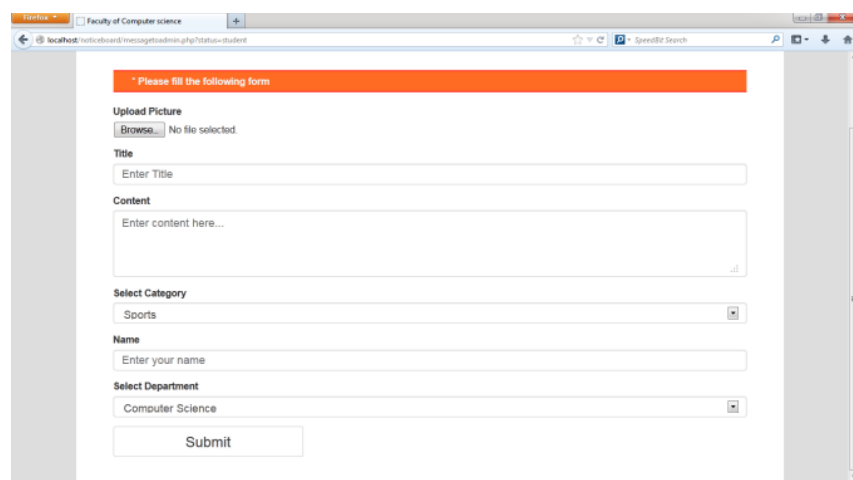

Fig. 10. User's form for uploading notice to administrators

The Fig. 11 below shows the output of general notice called news. The notice will display a short message that will be sent to the users' device as a real-time SMS, alerting them about new update on the notice board giving them hint to the notice. User can then go online at their convenient to read the notice in detail.

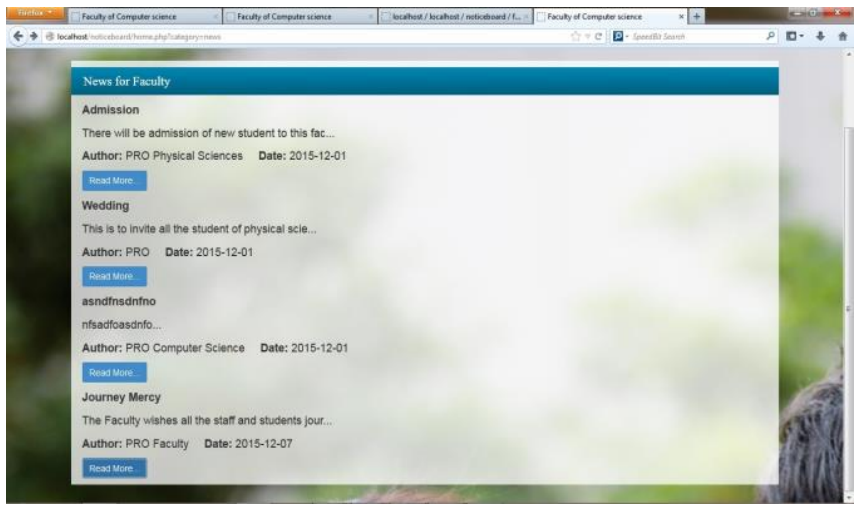

Fig. 11. General Notice.

The Fig. 12 below shows the detail of a notice when the user clicked on the "read more detail" for details of the notice to be shown. 


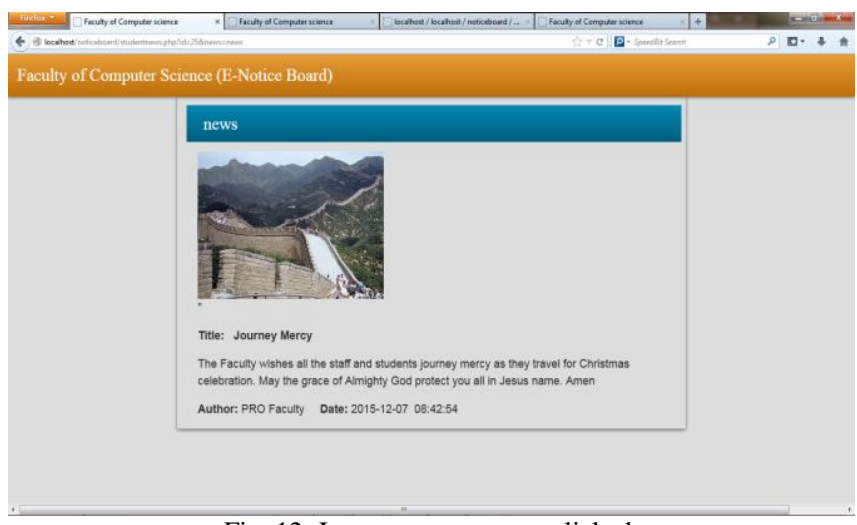

Fig. 12. Journey mercy news clicked.

The Fig. 13 below shows the output of notice forwarded to the administrator for approval. From the menu shown in the figure below, the upload information shows the page where the admin approve and upload notice received from users, the moment admin click on approve in any of the notice, an upload is made and an SMS alert will be forwarded to all registered users in that category, admin can delete any notice he/she choose not to upload based on the notice content after an interval of two weeks, once admin clicked to open and read a notice received from a user, the viewed column on the news notice will turn to yes as shown in Fig. 13 below.

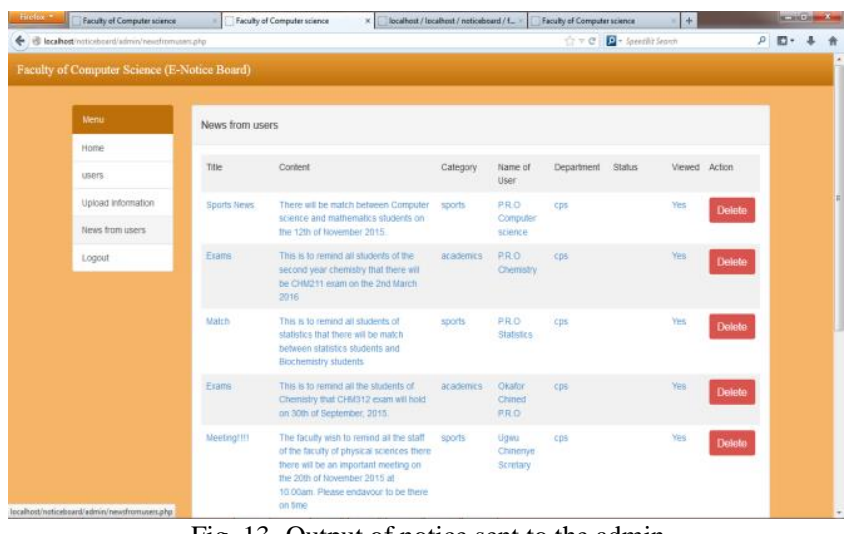

Fig. 13. Output of notice sent to the admin.

\section{CONCLUSION}

The deployment of our ENB web application brings an advanced means of passing notices around in the University faculties. It has the capability to disseminate notices in a simple, efficient and well-organized manner compare to the convectional paper based wooden notice board system. Human traffic will reduce at the notice board location with the use of the ENB since information on the notice boards can be accessed electronically on the ENB. Moreover, users will be able to forward notices to be approved by the admin before uploading and the Short Messaging Service (SMS) makes the system to efficiently function well, members receives alert on their registered cell phone numbers or emails with the link to view the notice when update is made on the notice board. On monitoring the posted notices, the administrator can either delete or archive the outdated notices in order to control the accumulation of notices in the database. The output can be displayed on large electronic board, developed as an online web application in the PC, tablet or cell phones. Security of notice is guaranteed as only the faculty admins approves and uploads notice and the department posting notices have an assigned key to do so. The system operates at a high level of efficiency, all the students and staff members associated with the system understands its advantages, also the system solves the problem it was intended to solve as requirements specification. Finally, the uses of papers and energy have been reduced by $90 \%$ through using the ENB and we realized that this research work saves time, energy and hence environment. Cost of printing and photocopying is also reduced as information can be given to a large number of people from our fingertips. In general, the ENB results have an improvement over the existing notice boards used in the University faculties.

\section{REFERENCES}

[1] V. C. Osamor, O. S. Aloba, and I. P. Osamor, "From Wooden to Digital Notice Board (DNB): Design and Implementation for University Administration", International Journal of Electrical \& Computer Sciences, IJECS-IJENS Vol:10 No:02, Pp. 79-83. April 2010.

[2] N. Villar, V. L. Kristof. and H. Gellersen, "A physical notice board with digital logic and display," Embedded Interactive Systems Group, Computing Department Lancaster University, UK.

[3] A. H. Roslilee, A. J. Faizan, A. M. Siti, and Ab. H. Norliwa, "Assessing the Effectiveness of Conventional Notice Board in Universities' Information Delivery",Gading Business and Management Journal, Vol. 15, pp. 3-8. 2011.

[4] N. Rasika, B. Roshni, M. Riya, and B. Harsha, "Wireless e-Notice Board with Text to Audio Conversion" Journal of Emerging Technologies and Innovative Research (JETIR). Vol. 1. No.7,Pp. 23 30. Dec 2014

[5] B.Adkins, E.Grant "Backpackers as a community of strangers: the interaction order of an online backpacker notice board". Qualitative Sociology Review, 3 (2), 2007.

[6] S.K. Semakuwa, F.U. Rashid, D.C. Fungo, R.Y. Mbwana, "Migrant From On Wall Notice-Board To An Online Announcement Displaying System For Tanzanian, College's" International Journa Of Research In Computer Applications And Robotics. Issn 23207345. Vol.2 Issue.9, Pp. 88-95. September 2014.

[7] S. Karthikeyan, "Ontogeny Smart Bulletin Board," ARPN Journal of Engineering and Applied Sciences. ISSN 1819-6608. Vol. 10, NO. 5, March 2015.

[8] N.L. Ndidiamaka, "The Impact of Information and Communication Technology (Ict) Compliant Librarians on Library Services Delivery In Academic Library," The Case Of National Open University Of Nigeria (Noun) Library. The International Journal of Engineering and Science (IJES), ISSN (e): 2319 - 1813, ISSN (p): 2319 - 1805, Vol 2, Issue 8, pp 37-43, 2013

[9] G.B. Devchoudhari, "ICT and Electronic Library: Management and Delivery within the Traditional Library," Gauhati University, Guwahati, 5th Convention Planner-2007, December 2007, pp. 344 350.

[10] C. Nwezeh, "The Use of ICT in Nigeria Universities," A Case Study of ObafemiAwolowo University, Ile-Ife 2010.Pp. 9-16

[11] G. Heiberger, and R. Harper, "Have You Face booked Astin Lately? Using Technology to Increase Student Involvement", New Directions for Student Services, No. 124, Winter 2008. Wiley Interscience.

[12] Nelson, M. (1994) We have the information you want, but getting it will cost you! Crossroads 1(1), ACM Press.

[13] Ljungberg, F. and Sørensen, C. (1998). Are you pulling the plug or pushing up the daisies? In: Proceedings of Thirty-First Hawaii International Conference on System Sciences (HICSS'31), Hawaii. IEEE Computer Society Press.

[14] P. Dourish, and S. Bly, "Portholes: Supporting Awareness in a Distributed Work Group," ACM 1992 Conference on Human Factors in Computing Systems, Monterey, CA, ACM Press. https://pages.cpsc.ucalgary.ca/ saul/601.13/readings/portholes.pdf.

[15] R. Fish, R. Kraut, R. Root, \& R. Rice, "Video as a technology for informal communication," In: Communications of the ACM 36(1) pp. 48-61 ACM Press 1999 http://www.comm.ucsb.edu/faculty/rrice/A42FishKrautRootRice1993 .pdf. 
[16] G. Fitzpatrick, S. Kaplan, \& S. Parsowith, "Experience in Building a Cooperative Distributed Organization," Lessons for Cooperative Buildings. In: Proceedings of First International Workshop on Cooperative Buildings (CoBuild'98), pp. 66-79. Springer-Verlag. http://citeseerx.ist.psu.edu/viewdoc/download?doi=10.1.1.25.2901\&re $\mathrm{p}=$ rep $1 \&$ type $=$ pdf

[17] H. Nakanishi, C. Yoshida, T. Nishimura, \& T. Ishida, "FreeWalk: Supporting Casual Meetings in a Network," In: Proceedings of CSCW'96, pp. 308-314. ACM Press 1996.

[18] F. Viegas, \& J. Donath, "Chat Circles," In: Proceedings of CHI'99, pp 9-16, ACM $\quad 2000$. http://alumni.media.mit.edu/ fviegas/projects/chatcircles/.

[19] J. Redstrom, P. Dahlberg, P. Ljungstrand and L. E. Holmquist, "Designing for Local Interaction," Applied research on art and technology and Mobile Informatics Research Groups, Viktoria Institute, Box 620, SE-405 30 Göteborg, Sweden.

[20] F. Redhead, and M. Brereton, "Designing interaction for local communications," an urban screen study. In: Proceedings of Interact 09: 12th IFIP TC13 Conference on Human-Computer Interaction, pp. 24 -28 Aug 2009

[21] B. Merai, R. Jain, R. Mishra, "Smart Notice Board," International Journal of Advanced Research in Computer and Communication Engineering. ISSN (Online) 2278-1021, ISSN (Print) 2319-5940. Vol 4, Issue 4, April 2015.

[22] A. Cooper and J. Matthias, "Communications Case Study, Using notice boards effectively". Published: August 2011. Pp. 1-10.

[23] M. Beveridge, "An online student notice board". Undergraduate at University of Birmingham, Blog, Published on May 29, 2013.

[24] J. L. Bernier, M. Barchéin, A. Canas, C. G. Valenzuela And J. J. Merelo, "The Services A University Website Should Offer," 2011.

[25] J. Muller, O. Paczkowski, and A. Kruger "Situated Public News and Reminder Displays," University of Munster, Germany. LNCS 4794, pp. 248-265, 2007.

[26] J. Brown, B. Shipman, R. Vetter SMS: The Short Message Service," University of North Carolina Wilmington. http://uncw.edu/itsd/documents/Computer-SMS_pdf.pdf.

[27] S. Dillo, "Build mobile text messaging into your web apps," Blog, November2011.http://www.ibm.com/developerworks/library/mo-smsweb/.

[28] H. Brignull, and Y. Rogers, "Enticing People to Interact with Large Public Displays in Public Spaces," In: INTERACT 2003, Pp. 17-24. IOS Press, Amsterdam (2003).

[29] Y. T. Chung, "Bluetooth Announcement System," Bachelor's thesis, UTM. 2009. Pp 1-8, http://ir.fsksm.utm.my/305/1/E-Thesis.pdf.

[30] Wikipedia, "Bulletin board",the free encyclopedia. Blog, Dec. 2007. http://en.wikipedia.org/wiki/Bulletin_board.

[31] F. Kamdar, A. Malhotra and P. Mahadik, "Display Message on Notice Board using GSM," Advance in Electronic and Electric Engineering. ISSN 2231-1297, Vol. 3, Number 7. pp. 827-832. 2013.

[32] G. Kasilingam, M. Ramalingam and C. Sekar "A Survey of Light Emitting Diode (LED) Display Board " Indian Journal of Science and Technology, ISSN (Print): 0974-6846, ISSN (Online): 0974-5645, Vol 7(2), 185-188, February 2014.

[33] Km. R. Singh, S. Manzoor, R. Shukla, A. Alung and P. Aggarwal,"Keyboard Driven Electronic Notice Board, " International Journal of Advanced Technology in Engineering and Science Vol No.03, ISSN (online): 2348-7550 Issue No. 04, April 2015. www.ijates.com.

[34] T.H.Riyad,"Virtual Notice Board,"www.bissoft.tk, 2003.

[35] J.P. Dixion, "NoticeBoardPro," http://www.noticeboardpro.com/index.html, 2011

[36] A. S. Padmashali, D. V Bhat, G. A. Moonisha and U. C. Venkatesh, "Electronic Notice Board for Professional College", International Journal of Science, Engineering and Technology Research (IJSETR), ISSN: $2278-7798$. Volume 3, No. 6, June 2014.

[37] T. Mansikkaniemi, T. Keinonen, H. Wikberg, K. Tampere, V. Helsinki "Wireless family bulletin board," Patent Application Publication, United States, May 30, 2002.

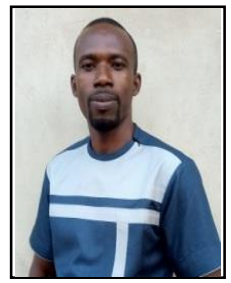

Kingsley N. Omeje holds B.Sc. degree in Computer Science from Ebonyi State University, Nigeria. M.Sc. degree in Computer Science at the University of Nigeria, Nsukka and he is currently pursuing his Ph.D. at the University of Nigeria, Nsukka. . He is a member of a couple of international Information and Communications Technology societies. His areas of research interest include: Software Engineering and Security, Intelligent Systems and Networking.

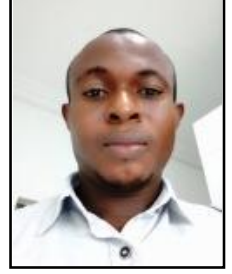

Henry O. Osuagwu obtained his B.Eng. Electronic Engineering and M.Eng. Communication Engineering from University of Nigeria, Nsukka, Nigeria in 2011 and 2016 respectively. $\mathrm{He}$ is currently a Ph.D. student in the Department of Electronic Engineering, University of Nigeria, Nsukka, Nigeria. He is a member of Nigerian Society of Engineers (NSE) and a registered COREN engineer. $\mathrm{He}$ is a Lecturer in the Department of Electrical Engineering, Nigeria Maritime University, Okerenkoko, Delta State, Nigeria. His research interests include Wireless Communication, Radio Resource Management, Network Security, and Cognitive Radio in Wirelesss Sensor Networks.

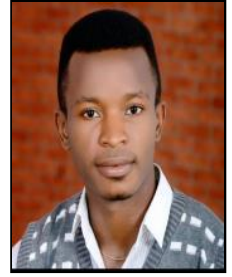

Chimezie F. Ugwu holds a Bachelor of Science degree in Computer Science And Statistics from the University Of Nigeria Nsukka. Master of Science Degree in Computer Science at the University of Nigeria, Nsukka and he is currently pursuing his $\mathrm{Ph} . \mathrm{D}$. at Ebonyi State University, Nigeria. He is a Lecturer in the Department of Computer Science, Institute of Management and Technology, IMT Enugu, Nigeria. His area of research interest includes: Ethical hacking and Network Security. 